\title{
Testing for bubbles in indirect property price cycles
}

Article

Accepted Version

Brooks, C., Katsaris, A., McGough, T. and Tsolacos, S. (2001) Testing for bubbles in indirect property price cycles. Journal of Property Research, 18 (4). pp. 341-356. ISSN 1466-4453 doi: https://doi.org/10.1080/09599910110079640 Available at https://centaur.reading.ac.uk/35969/

It is advisable to refer to the publisher's version if you intend to cite from the work. See Guidance on citing.

Published version at: http://dx.doi.org/10.1080/09599910110079640

To link to this article DOI: http://dx.doi.org/10.1080/09599910110079640

Publisher: Routledge

All outputs in CentAUR are protected by Intellectual Property Rights law, including copyright law. Copyright and IPR is retained by the creators or other copyright holders. Terms and conditions for use of this material are defined in the End User Agreement.

\section{www.reading.ac.uk/centaur}

\section{CentAUR}

Central Archive at the University of Reading

Reading's research outputs online 
This is an Author's Accepted Manuscript of an article published in the Journal of Property Research (2001) [copyright Taylor \& Francis], available online at: http://www.tandfonline.com/ 10.1080/09599910110079640 


\title{
Testing for Bubbles in Real Estate Price Cycles
}

\author{
Chris Brooks (author for correspondence) \\ ISMA Centre, Department of Economics, University of Reading, Whiteknights, Reading RG6 6BA, UK \\ E-mail: C.Brooks@ISMAcentre.reading.ac.uk \\ Apostolos Katsaris \\ ISMA Centre, Department of Economics, University of Reading, Whiteknights, Reading RG6 6BA, UK \\ E-mail: A.Katsaris@ reading.ac.uk \\ Tony McGough \\ PPM UK Limited, Laurence Pountney Hill, London, EC4R 0EU, UK \\ E-mail: Tony.McGough@ppm-uk.com \\ Sotiris Tsolacos \\ Jones Lang LaSalle, 22 Hanover Square, London, W1A 2BN, UK \\ Tel: +44 (0) 207399 5750; Fax: +44 (0) 207399 5103; E-mail: sotiris.tsolacos@eu.joneslanglasalle.com
}

\begin{abstract}
This paper investigates whether the prices of UK equity-traded property stocks over the past fifteen years contain evidence of a speculative bubble. Speculative bubbles are generated when investors include the expectation of the future price in their information set. In the presence of speculative bubbles, positive expected bubble returns will lead to increased demand and will thus force prices to diverge from their fundamental value. The present analysis draws upon the methodologies adopted in various studies examining price bubbles in the general stock market. Fundamental values are generated using two models: the dividend discount and the Gordon growth. Variance bounds tests are then applied to test for bubbles in UK property asset prices. Finally, cointegration analysis is conducted to provide further evidence on the presence of bubbles. Evidence of the existence of bubbles is found but these appear to be transitory and concentrated in the mid-to-late 1990s. Investors in property stocks should be aware that in periods when bubbles are present the market does not move on the basis of the fundamentals and abrupt price corrections can occur.
\end{abstract}

May 2000

Acknowledgement: The authors are grateful to participants at the sixteenth annual American Real Estate Society meeting in Santa Barbara, March 29 - April 1, 2000, for useful comments on a previous version of this paper. The usual disclaimer applies. 


\title{
Testing for Bubbles in Real Estate Price Cycles
}

\begin{abstract}
This paper investigates whether the prices of UK equity-traded property stocks over the past fifteen years contain evidence of a speculative bubble. Speculative bubbles are generated when investors include the expectation of the future price in their information set. In the presence of speculative bubbles, positive expected bubble returns will lead to increased demand and will thus force prices to diverge from their fundamental value. The present analysis draws upon the methodologies adopted in various studies examining price bubbles in the general stock market. Fundamental values are generated using two models: the dividend discount and the Gordon growth. Variance bounds tests are then applied to test for bubbles in UK property asset prices. Finally, cointegration analysis is conducted to provide further evidence on the presence of bubbles. Evidence of the existence of bubbles is found but these appear to be transitory and concentrated in the mid-to-late 1990s. Investors in property stocks should be aware that in periods when bubbles are present the market does not move on the basis of the fundamentals and abrupt price corrections can occur.
\end{abstract}

May 2000 


\section{Introduction}

Quantitative research seeking to model the price variation in traded real estate stocks usually concentrates on the fundamental forces that are responsible for price movements through time. Much research, especially by US scholars, has placed emphasis on a set of variables that captures the effect of the changing business climate, conditions and expectations in the investment markets on the price and returns of property stocks. Authors have explored the capacity of different methodologies to test empirically $a$ priori relationships and overcome estimation problems (see for example Chan et al, 1990; Liu and Mei, 1992; McCue and Kling, 1994; Ling and Naranjo, 1997; and for a review of the main characteristics of commonly encountered methodologies see Brooks and Tsolacos, 1999). The existing literature has not, however, allowed for the possibility that current or future prices are dependent on events that are extraneous to the underlying property market and the business climate. An example of such an event is the self-fulfilling prophecy where expectations about prices actually materialise and underpin the building up of price bubbles.

There has been a long tradition of studying the theory and models of price bubbles in the general stock market. The fundamental value of a security, according to Lucas (1978), is the present value of all the security's future cash flows. The divergence of the actual price of a financial asset from its fundamental value is called a bubble. Speculative bubbles have the special characteristics that they are persistent, systematic and exhibit increasing deviations of prices from their fundamental values (Santoni, 1987). Speculative bubbles can be created by exogenous factors that have no correlation with the factors that affect fundamental value, by the incorrect estimation and analysis of market fundamentals, or by the presence of informational asymmetries and herd behaviour in the market itself. According to Flood and Hodrick (1990), speculative bubbles are self-fulfilling prophecies.

Speculative bubbles are generated when investors include the expectation of the future price in their information set. In a universe comprising a finite number of securities and investment horizons, the expected future price will have a significant weight in the investor's information set and will affect their demand and supply functions. Under these conditions, the actual market price of the security, that is set according to demand and supply, will be a function of the future price and vice versa. In the presence of speculative bubbles, positive expected bubble returns will lead to increased demand and will thus force prices to diverge from their fundamental value. If the expectation of positive excess returns remains unchanged and the investor is compensated for the increased risk of bubble collapse, then these excess or abnormal returns will be realised in an increasing fashion. Gilles and LeRoy (1992) have shown that every continuous dynamic price system can be divided into two parts: a fundamental and a bubble component. The present value of the fundamental price can be described as a linear combination of its parts, i.e. the future dividends. However, when a speculative bubble is present, the bubble component is larger than the 
linear combination of its future elements. This in fact means that the bubble is actually bigger than the present value of its expected future price.

Following on from the theoretical definition of financial bubbles, there is extensive literature that explores in detail the methodological issues relating to the detection of bubbles. Key to the study of bubbles is the construction of a model that produces the fundamental values and it is thus vital that this model is well specified. It is submitted that a mis-specified model can be misleading and produce false fundamental values. On a similar point, testing for the presence of bubbles is another well-analysed area and alternative tests have been put forward for their detection. Existing research has highlighted the pitfalls of different tests and authors have been in a constant search for techniques that overcome previous methodological problems. This debate can be followed in a large number of studies including Flood and Garber (1980), Kleidon (1986), West (1987), Hamilton and Whiteman (1985), Campbell and Shiller (1988), and Charezma and Deadman (1995).

Based on the relevant finance literature, we can argue that, when current market prices of traded property assets depend positively on expected asset returns and prices, a price bubble will be observed which will be driven by self-fulfilling elements in expectations. In such situations, the expectations of price changes drive actual price changes independently of market fundamentals. Therefore, the question is whether market fundamentals are constantly responsible for property asset price variation or a bubble drives current prices in specific periods.

The very limited quantity of research which has sought to explicitly detect bubbles in the property market has concentrated on the housing market. Abraham and Hendershott (1996) construct an equation of real house price appreciation and an error term. The former is related to a number of variables that drive house prices. The error term is assumed to pick up the effects of lagged values of the appreciation rate in house prices, the gap between the equilibrium and actual real price levels a period ago and random effects on the actual real price appreciation. The bubble in this framework is the actual real appreciation rate in house prices in the previous period, which also represents speculative pressures in the market. These authors found that house prices in the US North East and West coastal cities were above those suggested by the fundamentals. Bourassa and Hendershott (1995) applied the same model in Australian capital cities, but they did not find very significant elements of bubbles.

More recently, Hendershott (2000) has looked for the presence of bubbles within the Sydney office market. This model looked at the fundamental value of an office in terms of the 'present value of expected future net operating income' (excluding operating costs). The extent to which future rents are above or below their equilibrium value is linked to the relationships between the natural and actual vacancy rate, net returns and the real financing rate, and the need to cover replacement costs. This paper used 
expectations of future vacancy rates to forecast rental growth and supply, and thus develop a model for investors' assumptions of future cash flows. Thus, the fundamental value could be compared to the replacement cost of property and times of over and under valuation. From this, Hendershott saw the property peak of 1989 and trough of 1992 being explained only by 'blind extrapolation', as future expectations should have shown declining fundamental values.

These studies however do not apply the customary and standard tests for bubbles. The statistical significance of the lagged price appreciation rate as a measure of bubbles is questionable econometrically especially when the model is not well specified and may lead to misleading results as the price and the appreciation rate may contain a bubble that is already included in the fundamental values. The judgement about the presence of bubbles is based on a simple comparison of the actual prices with those produced by simulation analysis. Moreover, since a well known concern in the bubbles literature is the plausibility of the model producing the fundamental values, the above studies do not undertake any diagnostic checking to ensure that the results are not biased by mis-specification problems. Scott (1990), on the other hand, conducted commonly used tests to examine whether the actual prices of land and REITs deviated from their fundamental values. Scott used an inter-temporal capital asset pricing model to develop a model of market fundaments and to obtain the fundamental values of land and REITs. Regression tests and mean tests were applied to test for bubbles and it was found that REIT prices had deviated from their fundamental values, therefore suggesting the presence of bubbles.

The focus of the present study is to detect bubbles in the prices of UK property traded stocks and it represents the first attempt in the UK property investment context. The analysis draws upon the methodologies adopted in the many studies examining price bubbles in the general stock market. Fundamental values are generated using two models: the dividend discount and the Gordon growth. Variance bounds tests are then applied to test for bubbles in the UK property asset prices. Finally, cointegration analysis is conducted to provide further evidence on the presence of bubbles.

The remainder of the paper is organised as follows. The next section in this paper summarises the methodology and features of the data. Section three provides the results of the tests and section four concludes.

\section{Methodology and data}

There are several approaches to test for the presence or otherwise of speculative bubbles which can be grouped into three main categories: tests for bubble premiums, tests for excess volatility and tests for the cointegration of dividends and prices. In this study we apply the latter two. 


\section{Excess Volatility Tests}

This category of tests for bubble existence involves an examination of the stock market's variance and the application of tests for excess volatility. In general, if a speculative bubble is present, the variance of the stock price will be greater than the variance of the fundamental price. Although Friedman (1953) claims that the presence of speculators decreases the volatility of prices, Hart and Kreps (1986), Baumol (1957) and Kohn (1978) show that speculators and speculative bubbles cause a significant increase in price volatility.

Tests for the presence of excess volatility are based on a comparison of the variance of actual prices with the variance of fundamental prices. In most cases, the fundamental prices are constructed using ex-post analysis, but several researchers try to model and forecast dividend series in order to construct fundamental prices that are similar to the prices perceived by investors. Shiller (1981) performed the first tests for excess volatility by comparing the volatility of actual prices and fundamental prices that were constructed using ex-post analysis. The variance of these prices was then compared with the variance of actual stock prices. Variance bounds tests were built on the assumption that the variance of actual prices, $\operatorname{Var}\left(p_{t}^{a}\right)$, should be smaller than the variance of fundamental prices, $\operatorname{Var}\left(p_{t}^{f}\right)$, since:

$$
\operatorname{Var}\left(p_{t}^{f}\right)=\operatorname{Var}\left(p_{t}^{a}\right)+\operatorname{Var}\left(u_{t}\right) \geq \operatorname{Var}\left(p_{t}^{a}\right)
$$

where $u_{t}$ is an error term representing the difference between actual prices and the fitted price obtained from the fundamental model.

A key task before applying variance criterion (expression (1)) is to construct the fundamental values. The first model to construct fundamental values in this study is based on the classical dividend discount methodology. The exact relationship that gives the fundamental values draws on Shiller's (1981) analysis and is given by Equation (2):

$$
p_{t}^{f}=\sum_{n=1}^{T} \frac{1}{(1+i)^{n}} d_{t+n}+\frac{1}{(1+i)^{T-n}} P_{1 / 1998}
$$

where $p_{t}^{f}$ is the fundamental value to be estimated, $d_{t}$ is the dividend of period $t$, and $P_{1 / 1998}$ is the truncation approximation of all out of sample dividends and $i$ is the discount rate. 
According to Equation (1) the fundamental values are constructed using historical dividend and price information only. This equation constructs fundamental values assuming investor perfect foresight regarding the dividend and the discount rate. In the present study the discount rate $i$ is the average FT Real Estate return for the period January 1986 to January 1998. The dividend $d$ represents a cash dividend and is obtained from the FT Real Estate dividend yield (to be explained in the data section). In addition to this, the replacement of the infinite dividend series with the price of the FT Real Estate for January 1998 is performed under the implicit assumption that the dividend generating process will be the same for out of sample dividends.

The second model used to construct fundamental values is the Gordon growth model. This model, given by Equation (3), is perceived in the existing literature as a framework that generates more practical fundamental values.

$$
P_{t}^{f}=\frac{(1+g)}{(g-i)} \mathrm{D}_{\mathrm{t}-1}
$$

where $g$ is the dividend growth rate, $i$ is the discount rate and $\mathrm{D}$ is the dividend.

The fundamental values estimated from the above model are based only on information available in December 1991 and are 'updated' every month as new information on dividends is made known. In the estimates of this study, the discount rate $(i)$ used is the average FT real estate real return for the period January 1986 - December 1991 and the dividend growth rate $(g)$ is the average growth of real cash dividends for the same period. These values are identical to the ones contained in the investor's information set in January 1992.

The success of the variance bounds tests to detect bubbles is much dependent on the appropriateness of the fundamental values constructed. This is evident in the existing literature that informs the researcher of the potential pitfalls and proposes alternative methodologies to be applied. Shiller (1981) used price and dividend data for the S \& P 500 Index for the period 1971-1979 and de-trended the two time series for inflation and earnings volatility. The results of the variance bounds tests showed that the condition (1) was almost always violated by the data, indicating that a bubble was present in the market. A limitation of this method is that the substitution of the infinite sum of discounted dividends with the actual price of 1998 makes the implicit assumptions that the market efficiently priced future cash flows in the cut off year and that the dividend process remained unchanged for out of sample dividends. Also, there is a danger that the cut-off price might contain a bubble that will not be detected as it will be included in the fundamental price. Marsh and Merton (1986) show that the construction of fundamental prices using an inappropriate 
assumption for the dividend process can lead to the wrong conclusion regarding bubble presence, especially if dividends are generated from a non-stationary process (Dybvig and Ingersoll (1996)).

In a more general critique, Kleidon (1986) shows that excess volatility might not be caused by the presence of a bubble, but rather by investor irrationality or fundamental model mis-specification. In essence, Kleidon states that fundamental prices constructed with ex-post data are different to prices observed by investors, since investors' forecasts are made under uncertainty. Perfect forecast prices are constructed with $100 \%$ certainty so they represent only one of the infinite economies faced ex-ante by investors.

LeRoy and Porter (1981) built fundamental values that used dividends that were forecast based only on historical information, but after testing their model on S\&P 500 data, they come to the same result that equation (3) does not hold. Dezhbakhsh and Demirguc-Kunt (1990) use an ARMA model to forecast dividend series and construct fundamental values using these expected dividends. Using the same data for the S\&P 500 they cannot reject the no-bubble hypothesis and find that fundamental and actual values have the same volatility. West (1987) uses the same ARMA modelling methodology, but decomposes the variance bounds test into three separate tests of model specification, data consistency and excess volatility. His methodology comes to the conclusion that a bubble is existent in the data.

Overall, Flood and Garber (1980) argue that most of the models for fundamental price construction are mis-specified, and are not formed with an information set similar to the one that investors use, and more importantly, they exclude relevant variables. Furthermore, they use dividend and price series that are nonstationary, which could lead to biased variance estimates. These problems can render variance bound tests unreliable and have encouraged the development of bubble tests based on the concept of cointegration.

\section{Non-Stationarity and Cointegration Tests}

Diba and Grossman (1988a and 1988b) show that if:

(i) the stock price depends exclusively on future dividends

(ii) there are no rational speculative bubbles

(iii) dividends are stationary in the mean

then prices will be stationary. However, even if dividends and prices are non-stationary, if they are cointegrated then the no-bubble hypothesis cannot be rejected. Hence an intuitively simple test for bubbles is an investigation of whether the price and dividend series are cointegrated. If they are, there cannot be a speculative bubble in the series since cointegration implies that prices and dividends are bound together by some relationship in the long run. Nevertheless, the lack of cointegration is not a sufficient condition to prove the existence of bubbles since the model might exclude significant variables that affect stock prices and that are not stationary. In their survey, Diba and Grossman find that the dividend and price series for 
the S\&P 500 are difference stationary so they reject the bubble hypothesis, and after testing for cointegration, they verify their result of no bubble since prices and dividends are cointegrated. However, Dickey Fuller tests for unit roots give unreliable results for samples of the size used in the Diba and Grossman study (less than 100 observations) - see Evans and Savin (1984).

Campbell and Shiller (1987) come to the same conclusion by testing the difference of prices and discounted dividends for stationarity. They use only historical information to forecast dividends and returns and test their model on U.S. stock price and dividend data. Their results show that the linear combination of prices and discounted dividends is an integrated series of order one, i.e. that the series are not cointegrated, so there is evidence of a bubble, but they note that this methodology is very sensitive to the discount rate used. Fama and French (1988) show that prices follow a stationary evolutionary process for short term horizons, but this process varies as the time horizon is increased. According to their analysis, stock prices can be predicted in part, but the classic present value model does not hold because of the presence of collapsing and regenerating bubbles that cannot be detected. The presence of such bubbles is supported by Summers (1986) who claims that expectations, or bubbles that are based on expectations, might cause a significant temporary divergence of actual prices from their fundamental values, but such bubbles do not leave a statistical trace and so cannot be identified.

Johansen (1991) shows that a lack of cointegration of dividends and prices might not be caused by the presence of a bubble but by the lack of cointegration in reality caused by other factors. In addition, Evans (1991) states that cointegration tests cannot detect a large category of bubbles that are based on fundamentals. These intrinsic bubbles follow the same evolutionary process as the expected dividend and so they cannot be detected.

Finally, Campbell and Shiller (1988) have tried to model future stock prices using valuation ratios for U.S. stock market data. Their survey finds that although returns and dividend yields demonstrate very high volatility, they seem to be highly correlated with their fundamental values. This fact shows that there is a weak cointegrating relationship between dividends and prices and so the evidence of bubble existence is not reliable.

In conclusion, tests of stationarity and cointegration cannot absolutely give reliable results for bubble existence, since they are very sensitive to small samples and model mis-specification. However, they are the best analytical tool available to identify the presence of a long term relationship between actual prices and fundamental variables. The presence of a long-term relationship between dividends and prices can be an indication of bubble absence, but the tests greatly depend on the method employed to construct fundamental values. An appropriately specified model for constructing fundamental values must be based on a well-specified model of dividend prediction. 


\section{Description of data}

The series used to examine the existence of bubbles in the prices of real estate traded assets is the closing price of the Financial Times real estate share index on the first of the month. The dividend yield series is the Financial Times dividend yield series for the same index of real estate stocks. The data are obtained from Primark Datastream, and the sample period is defined January 1986 to January 1998 which gives 145 observations.

The dividend yield index used in this investigation is annualised and is derived from the monthly dividend yield. From the dividend yield in percentage terms we construct an actual 'cash' dividend time series. To obtain an actual 'cash' dividend time series we apply a common methodology and take the natural logarithm of the monthly dividend yield and then add the natural logarithm of the FT Real Estate index monthly close price. In this way, we obtain the logarithm of the implied actual annual dividend. This estimate is equivalent to a monthly cash dividend of the FT Real Estate index that is included in the dividend yield model.

Both the monthly 'cash' dividend and price series are transformed into real variables using the monthly United Kingdom producer price index. All the calculations and regressions are performed with real data, nevertheless the results are then transformed into nominal terms again for graphical representation to retain the visual image of the FT Real Estate index. Also, for graphical presentation purposes, a dividend and price index is constructed using monthly data. The indices take the value of 100 in January 1986. A plot of these indices is given in Exhibit 1. Some summary statistics for both nominal and real variables in levels and growth rate are shown in Exhibit 2. 
Exhibit 1: Monthly Plot of FT Real Estate index and the Dividend index

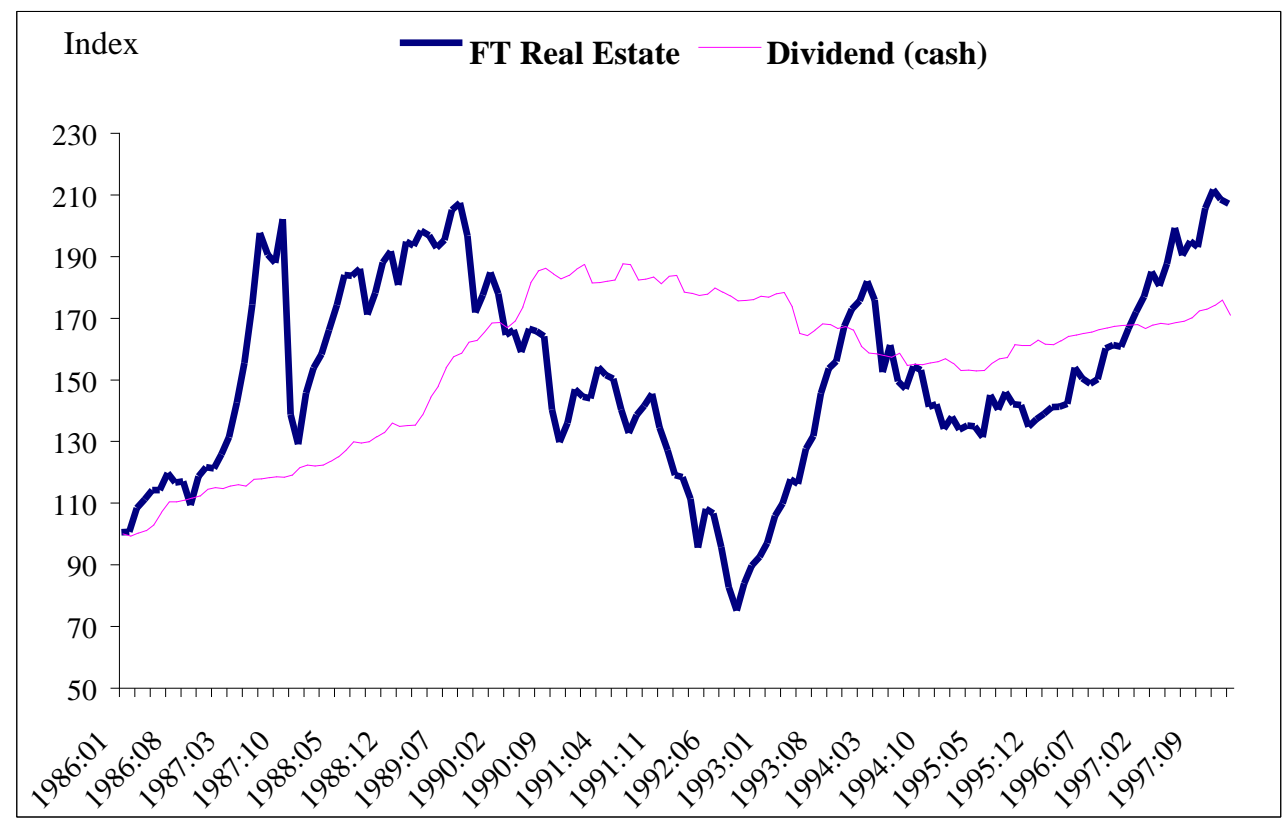

Exhibit 2: Summary statistics for FT Real Estate index and Dividend index

\begin{tabular}{lcccc}
\hline & \multicolumn{2}{c}{ FT Real Estate Index } & \multicolumn{2}{c}{ FT Real Estate Dividend index } \\
& Nominal & Real & Nominal & Real \\
\hline LEVELS & & & & \\
\hline Mean & 150.4 & 120.6 & 155.1 & 122.5 \\
Peak value & 211.2 & 192.1 & 187.7 & 153.7 \\
Peak date & $01-$-Oct-87 & 01 -Oct-87 & $01-$ Jan-91 & $01-$ Jul-90 \\
Ljung-Box Q-statistic (12 lags) & $653.82^{*}$ & $1001.56^{*}$ & $1277.35^{*}$ & $1356.04^{*}$ \\
Unit root - ADF statistic & -1.83 & -1.97 & -1.51 & -1.54 \\
\hline RETURNS/GROWTH RATES & & & & \\
\hline Average return/growth & $0.50 \%$ & $0.22 \%$ & $0.37 \%$ & $0.09 \%$ \\
Average return annualised & $6.05 \%$ & $2.67 \%$ & $4.47 \%$ & $1.09 \%$ \\
Standard deviation annualised & $22.77 \%$ & $22.84 \%$ & $4.77 \%$ & $4.85 \%$ \\
Maximum & $12.57 \%$ & $13.43 \%$ & $4.45 \%$ & $4.45 \%$ \\
Minimum & $-33.73 \%$ & $-38.00 \%$ & $-4.99 \%$ & $-5.20 \%$ \\
Skewness & -1.65 & -1.64 & -0.26 & -0.15 \\
Kurtosis & 9.98 & 9.90 & 5.40 & 5.46 \\
Normality - Jarque Bera & $357.39 *$ & $350.22^{*}$ & $36.26 *$ & $36.94 *$ \\
Ljung-Box Q-statistic (12 lags) & 14.71 & 13.30 & $85.35^{*}$ & $75.99 *$ \\
Unit root ADF statistic & $-10.51^{*}$ & $-10.46^{*}$ & $-4.18^{*}$ & $-3.58^{*}$ \\
\hline * Denotes significance at the 1\% level & & &
\end{tabular}

From Exhibit 2, we can see that both the nominal and real price and dividend series are integrated series of order one (I(1)), according to the Augmented Dickey-Fuller tests. It is also clear that the two indices differ 
in their peak value and peak dates. The Ljung Box Q statistic indicates that the dividend series, but not the price series, are autocorrelated in their growth rate forms. This is to be anticipated, since it is well known that companies smooth changes in dividend payments over time, thus inducing autocorrelation in the observed series.

\section{Results}

Initially the dividend discount model described by Equation (1) is applied to construct the fundamental values. Following the construction of the fundamental values, a comparison of the variance of the actual market prices to that of fundamental values is made. The results are given in Exhibit 3 along with other descriptive statistics.

Exhibit 3: Actual and fundamental prices based on the dividend discount model (Equation (1))

\begin{tabular}{|c|c|c|}
\hline & FT Real Estate & Ex post fundamentals \\
\hline \multicolumn{3}{|l|}{ LEVELS } \\
\hline Mean & 150.4 & 122.7 \\
\hline Peak value & 211.2 & 141.1 \\
\hline Peak date & 01-Oct-87 & 01-Nov-97 \\
\hline Ljung-Box Q-statistic (12 lags) & $653.82 *$ & $326.5^{*}$ \\
\hline Unit root - ADF statistic & -1.83 & -1.75 \\
\hline \multicolumn{3}{|l|}{ Variance Bounds Tests } \\
\hline Variance & $105,619.8$ & $42,483.1$ \\
\hline Variance bounds $F$-statistic & \multicolumn{2}{|c|}{$2.49^{*}$} \\
\hline $\mathrm{H}_{0}$ : VAR(Actual)<=VAR(Fundamentals) & \multicolumn{2}{|c|}{ Reject } \\
\hline$*$ Denotes significance at the $1 \%$ level & & \\
\hline
\end{tabular}

The results point to the excess volatility of the actual prices. The variance of the actual prices is $105,619.8$ and that of the constructed fundamental values 42,483.1. The variance of the actual value is then compared with the variance of the fundamental prices using an $F$-test. The $F$-statistic is significant at the one per cent level implying that that the variance of the actual FT Real Estate index is significantly greater than the variance of the fundamental values. Notwithstanding the criticisms of variance bounds tests described above, this is indicative of bubbles. 
Exhibit 4: Actual and fundamental prices based on Equation (1)

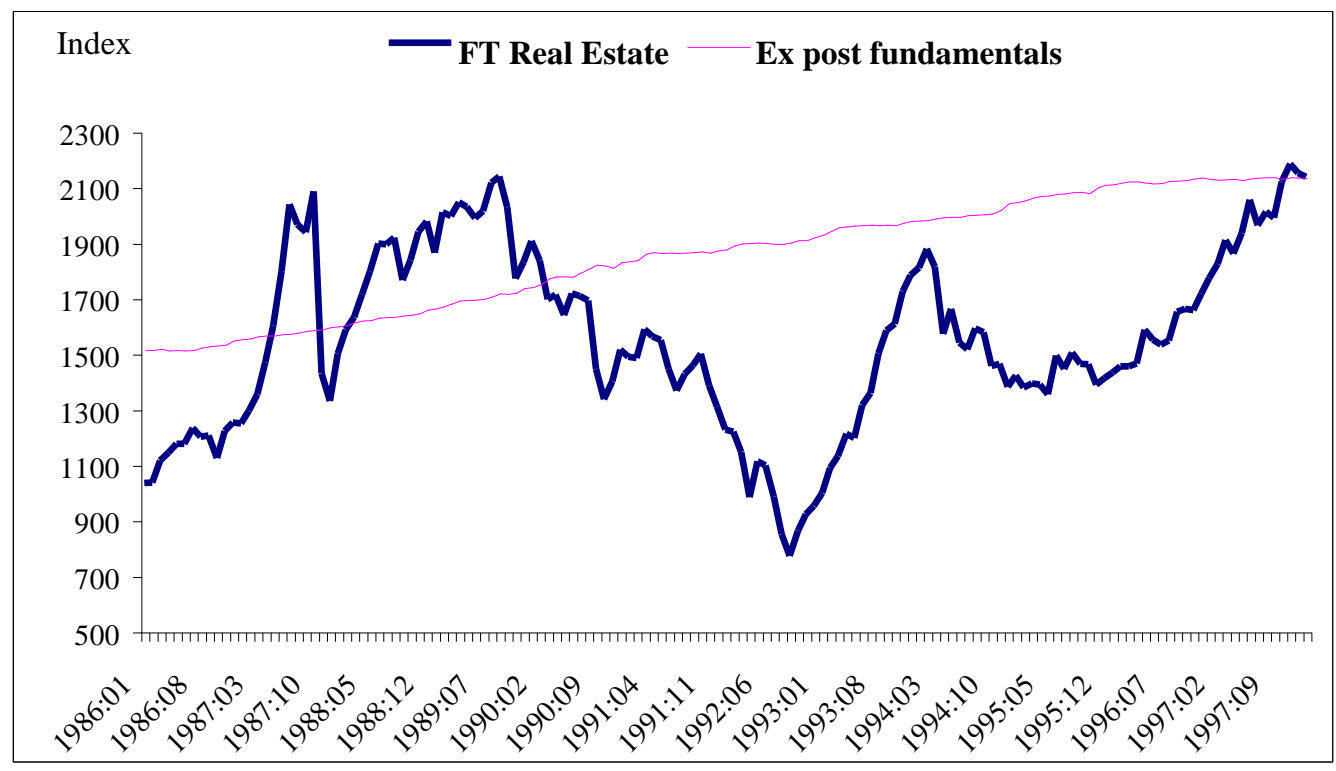

The actual FT Real Estate price index and the constructed fundamental values in the form of an index are plotted in Exhibit 4. It is clear from the graph that the fundamental values display little volatility around their trend unlike the volatility of the actual prices. The visual inspection of the plots of the two series also shows: (i) two periods when transient bubbles appear to be present (in the late 1980s); and (ii) a long period of under-valuation (throughout the 1990s), but as we approach the end of the sample period the fundamental values converge towards the actual values as the weight of the FT Real Estate actual truncation price increases in the fundamental price.

The only periods during which signs of a bubble exist are in 1987 and 1989. The late 1980s were a period of high rental growth across all sectors of the commercial property market. For example the IPD all property rent index showed annual increases of 15.2 per cent in December 1987, 23.3 per cent in December 1988 and another 16.2\% the following year. Such high growth rates may have provided the basis for forming very optimistic expectations that could drive the prices of traded stocks above their fundamental values. However, the stock market crash in October 1987 disturbed the upward growth of the traded real estate stocks and burst the apparent bubble that had been building up since mid-1987.

The long period of under-valuation that the dividend model predicts is partly explained by the fact that property company share prices have been trading at a discount to net asset value. Although such a situation in general reflects risks such as bad management, in the real property context it probably reflects risks associated with investing in property and engaging in property development. Many analysts have however argued that this discount to net asset value is not justified and that at times it has been unacceptably large. 
As noted in the previous section, the ex-post warranted prices are formed under a $100 \%$ certain environment so that they do not take into account the uncertainty investors are facing about future fundamental values and the inputs to these values are assumed to be constant, for example the discount rate. The serially autocorrelated dividends (see Exhibit 2) also make the fundamental values follow a smooth evolutionary process. In addition, the replacement of the infinite dividend series with the actual price of the FT Real Estate index for January 1998 is performed under the implicit assumption that the dividend generating process will be the same for out of sample dividends. If this price contains a bubble then this bubble will be included in the fundamental value and so it will not be observed, especially as we approach the truncation date.

In order to produce more realistic fundamental prices using the Gordon dividend growth model (Equation (2)), fundamental values for the period January 1992 to January 1998 are estimated using only data available at the start of this period (i.e. before the start of 1992). A constant discount rate and a constant dividend growth rate are again assumed for the entire post 1991 sample. The fundamental values estimated from the above model are based only on information available in December 1991 and are 'updated' every month as new information on dividends is made known. As noted in the previous section the discount rate used is the average FT Real Estate real return for the period January 1986 - December 1991 and the dividend growth rate is the average growth of real dividends for the same period. The results for this methodology are given in Exhibit 5 and the plot of the constructed fundamental values are shown in Exhibit 6.

Exhibit 5: Actual and fundamental prices based on the Gordon dividend growth model

\begin{tabular}{|c|c|c|}
\hline & FT Real Estate & Ex post fundamentals \\
\hline LEVELS & (Actual 1992-1998) & $(1992-1998)$ \\
\hline Mean & 145.2 & 137.8 \\
\hline Peak value & 211.2 & 149.4 \\
\hline Peak date & 01-Nov-97 & 01-Jul-93 \\
\hline Ljung-Box Q-statistic (12 lags) & $326.49 *$ & $452.75^{*}$ \\
\hline Unit root - ADF statistic & -1.75 & -2.7 \\
\hline Variance Bounds Tests & & \\
\hline Variance & $111,924.49$ & $3,035.51$ \\
\hline Variance bounds $F$-statistic & \multicolumn{2}{|c|}{$36.59 *$} \\
\hline $\mathrm{H}_{0}: \operatorname{VAR}($ Actual $)<=\operatorname{VAR}($ Fundamentals) & \multicolumn{2}{|c|}{ Reject } \\
\hline Unit root - ADF statistic of error & \multicolumn{2}{|c|}{-1.95} \\
\hline
\end{tabular}


Exhibit 6: Actual FT Real Estate index versus Gordon growth fundamental values



The fundamental values have remarkably lower variance than the actual FT Real Estate (3,035.51 versus $111,924.49$ of the FT Real Estate over the same period) and a very significant $F$-statistic is computed. This result shows that actual prices have more volatility than the fundamentals that should drive their evolutionary process. In Shiller's context, this would be evidence for bubble presence. Furthermore, the actual price error is nonstationary and so this rejects the no-bubble hypothesis as well. It is clear from Exhibit 6 that in the first half of 1992 the actual values and the fundamental values follow divergent trends. Another period that the actual values tend to move away from the fundamental values and begin to show evidence of a bubble is the second half of 1993. However, strong evidence of a bubble appears to emerge in late 1995 when the actual FT Real Estate diverges from the expected fundamental value, demonstrating increased volatility. The projected fundamental values imply a January 1998 value of the FT Real Estate of 1,394 points, significantly lower than the actual value of the FT Real Estate of 2,136 points.

However, a criticism of this approach is that the dividend growth and the discount rates are assumed to remain constant over time. Donaldson and Kamstra (1996) state that dividend growth has time varying conditional moments. Furthermore the discount rate is a function of investor risk aversion. As discussed above, if bubbles exist, the expected return has to grow geometrically for the bubble to survive. Even without bubbles, investors perceive different levels of risk through time and so they modify their discount rate accordingly. The use of a constant discount rate constructs fundamental values that tend to reject the no bubble hypothesis. Therefore, the bubble in the 1996 to 1998 period could partially have been the result of changing discount rates, especially in a period in which long-term interest rates followed a downward 
trend that has probably affected the discount rate. Over the same period yields in the underlying property market (IPD all property equivalent yields) have been continuously falling from 8.51 per cent recorded in October 1996.

In the light of these results, we undertake a cointegration test as a further investigation of bubbles in the FT Real Estate price index. As noted above, if dividends and prices demonstrate a long-term relationship, there is no bubble in real estate stock market prices. We use the Johansen test to identify the presence or otherwise of cointegrating vectors in the levels of prices and cash dividends. The methodology we use is similar to that of Diba and Grossman (1988a and 1988b). If prices and cash dividends are integrated of order one, which they both are (as seen from Exhibit 2), then a sufficient but not necessary condition for bubbles not to exist their linear combination must be stationary in levels. The results of the Johansen tests are given in Exhibit 7. Since there are only two variables in the system (prices and dividends), there can be at most one cointegrating vector. For cointegration, essentially one of the eigenvalues of the long run levels parameter matrix must be not significantly different from zero. If this is the case, the likelihood ratio test statistic will be larger than its corresponding critical value, and the null of no cointegration will be rejected.

Exhibit 7: Results of Johansen tests for cointegration

\begin{tabular}{ccccc}
\hline Eigenvalue & $\begin{array}{c}\text { Likelihood ratio } \\
\text { Test statistic }\end{array}$ & \multicolumn{2}{c}{ Critical values } & No of cointegrating vectors \\
& $(5 \%)$ & $(1 \%)$ & under the null hypothesis \\
\hline & & & & \\
0.08 & 17.47 & 19.96 & 24.60 & None \\
0.04 & 5.84 & 9.24 & 12.97 & At most 1 \\
\hline Cointegrating vector: & None & & & \\
\hline
\end{tabular}

Exhibit 7 shows that the Johansen test statistic is less than its $5 \%$ critical value, implying that there are no linear combinations of the series which are stationary, and therefore there is no cointegration over the sample period. Such a result would imply that there is no long run relationship between dividends and prices; theory would thus conclude that the presence of speculative bubbles cannot be rejected. It is quite possible that speculative bubbles may be transient - that is, appearing in the series during some time periods, but not during others. The cointegration method is not, however, free of criticism. A main concern is that the lack of cointegration may be caused by a structural change in the long-term relationship between dividends and prices and other factors being responsible for the lack of cointegration; it is thus also possible that there is still not a bubble in the price series. 


\section{Conclusions}

The present study looks for the presence of bubbles in the prices of traded property stocks in the UK. The sample period for this investigation is January 1986 to January 1998. The existing and extensive literature on bubbles in financial markets has provided significant evidence on alternative bubble testing methodologies. Authors have discussed the shortcomings of these methodologies and have attempted to improve the tests. Based on the findings of the literature this study undertakes two tests to detect bubbles in the FT Real Estate data: variance bounds tests and cointegration analysis. The fundamental values of the property stocks are constructed from a dividend discount model and the Gordon dividend growth model.

The genesis of the debate about the most appropriate measure of the fundamental values and the bubble testing approach is illustrated by the results of this study. The dividend discount method for generating ex post fundamental values points to the possible presence of bubbles. In mid- and late-1980s, such bubbles appear to be present in the FT Real Estate series. However, in the 1990s, the fundamental values based on this approach did not provide any signs of price bubbles but they strongly indicate that real estate stocks were undervalued, which is in line with the existing tradition to trade these stocks at a discount to net asset value. The cointegration approach of detecting asset price bubbles is suggestive of bubbles in the FT Real Estate series, suggesting that variables other than fundamentals drove stock prices in that period. One of these variables might be a speculative bubble. The findings of the Gordon dividend growth model reinforced the belief that the FT Real Estate Index was not driven by market fundamentals in the period end-1995 to beginning of 1998. Such transitory bubbles are in contrast with the general stock market, where historical evidence for long-lived speculative bubbles is overwhelming.

It is also possible that the fundamental relationship that links property prices to future dividends has changed due to shifts in investor preferences. It is particularly interesting to note in this regard that it is during the period of the late 1990s that the equity yield of the FT Real Estate Index has fallen markedly. This could well imply that the assumption of a constant discount rate could be more under pressure during this time period. If this were the case it may explain the performance of the models in the later period and their indication of a price bubble in the property sector at a time when the property shares have generally underperformed the stock market as a whole.

This research topic has not been fully explored by the present study, which represents one of the very few attempts to investigate bubbles in the direct or indirect real estate investment markets. It suggests, however, that there is evidence of bubbles in the prices of property company shares in the UK. This contention could be tested further employing additional methodologies to construct fundamental values such as arbitrage specifications and other ex ante techniques. More robust techniques for detecting bubbles are still being developed (see, for example, the paper by Hall et al., 1999), which may provide stronger 
conclusions; in the mean time, the current state of the art implies that bubble detection is as much an art as a science. However, the potential of the existing methodologies in identifying bubbles in real estate stocks should be fully explored so that investors who hold, or who are considering whether to hold, property stocks in their portfolios receive important information about the likely frequency and length of potential bubbles in the prices of these assets. Although any analysis of bubbles has its flaws, investors should, however, be aware that when bubbles build up, prices become subject to sudden adjustments that can be damaging for portfolio values. Such corrections can be triggered by even small changes in expectations or in response to economic or financial news, that under more "normal" market sentiment, would have had a much more muted effect on property stock prices.

\section{References}

Abraham,J.M. and Hendershott, P.H.: 'Bubbles in Metropolitan Housing Markets', Journal of Housing Research', 7(2) (1996) 191-207

Baumol W. J.: 'Speculation, Profitability and Stability', Review of Econometrics and Statistics, 39 (1957) 263-271

Bourassa, S. and Hendershott, P.: 'Australian Capital City Real House Prices, 1973-1993', Australian Economic Review, 3rd quarter 1995, 16-26.

Brooks, C. and Tsolacos, S.: 'Property Returns and the Macroeconomy', Journal of Property Research, 16(2) (1999) 139-52

Campbell J., Shiller R.: 'Cointegration and Tests of Present Value Models', Journal of Political Economy 95, (1987) 1062-1088

: 'Stock Prices, Earnings and Expected Dividends', Journal of Finance (1988) 43, 661-676

Chan, C.K., Hendershott, P.H. and Sanders, A.B.: 'Risk and Return on Real Estate: Evidence From Equity REITs', American Real Estate and Urban Economics Association Journal 18, (1990) 431-52.

Charezma, W.W. and Deadman, D.F.: 'Rational and Intrinsic Bubbles: A Reinterpretation of Empirical Results, Applied Financial Economics, 5 (1995) 199-202

Craine R.: 'Rational Bubbles: A Test', Journal of Economic Dynamics and Control, 17 (1993) 829-846

Dezhbakhsh ., Demirguc-Kunt A.: 'On the presence of Speculative Bubbles in Stock Prices', Journal of Financial and Quantitative Analysis, 25 (1990) 101-112

Diba B. T. \& Grossman H. I: 'The Theory of Rational Bubbles in Stock Prices', Economic Journal, 98 (1988a) 746-54

: 'Explosive Rational Bubbles in Stock Prices?', American Economic Review, 78 (1988b) 520530

Donaldson G. R., Kamstra M.: ' A New Dividend Forecasting Procedure That Rejects Bubbles in Asset Prices: The Case of 1929's Stock Crash', Review of Financial Studies, 9 (1996) 333-383 
Dybvig P., Ingersoll J. Jr.: 'Stock Prices Are Not Too Variable: A Theoretical and Empirical Analysis', Notes for the Finance Seminar, University of Chicago (1996)

http://www.gsm.ucdavis.edu/ gnbittli/Crash_Bash/index.html

Evans G. W.: 'Pitfalls in Testing for Explosive Bubbles in Asset Prices', American Economic Review, 81 (1991) 922-930

., Savin N. E.: 'Testing for Unit Roots:2', Econometrica (1984) 52, 1241-1269

Fama F. Eugene, French K. R.: 'Permanent and Temporary Components of Stock Prices', Journal of Political Economy, 96 (1988) 246-273

Flood R. P. \& Garber P.: 'Market Fundamentals Versus Price Level Bubbles: The first Tests', Journal of Political Economy, 88 (1980) 745-770

Hodrick J. R.: 'On Testing for Speculative Bubbles', Journal of Economic Perspectives, 4 (1990) 85-101

Friedman M.: 'Essays in Positive Economics’, University of Chicago Press, Chicago (1953)

Galbraith, John K.: 'The Great Crash (1929), Boston: Houghton Miffin Company (1988)

Gilles C., LeRoy S. F.: 'Bubbles and Charges', International Economic Review, 33 (1992) 323-339

Grossman S. J., Shiller R. J.: 'The Determinants of the Variability of Stock Market Prices', American Economic Review Papers and Proceedings, 71, (1971) 222-227

Hall, S.G., Psaradakis, Z., and Sola, M. 'Detecting Periodically Collapsing Bubbles: A Markov Switching Unit Root Test' Journal of Applied Econometrics 14 (1999) 143-154

Hamilton,J.D., Whiteman C. H.: 'The Observable Implications of Self-Fulfilling Expectations', Journal of Monetary Economics, 16 (1985) 353-373

Hart O. D., Kreps D. M: 'Price Destabilizing Speculation', Journal of Political Economy, 94 (1986) 927952

Hendershott, P.H.: 'Property Asset Bubbles: Evidence from the Sydney Office Market', Journal of Real Estate Finance and Economics, 20(1) (2000) 67-81.

Johansen S.: 'Estimation and Hypothesis Testing of Cointegrating Vectors in Gaussian Vector Autoregressive Models', Econometrica, 59 (1991) 1551-1580

Kleidon A. W.: 'Variance Bounds Tests and Stock Price Valuation Models', Journal of Political Economy (1986) 94, 953-1001

Kohn M.: 'Competitive Speculation', Econometrica, 46 (1978) 1061-1076

LeRoy S. F., Porter R. D.: 'The Present Value Relation: Tests Based on Implied Variance Bounds', Econometrica, 49 (1981) 555-574

Ling, D. and Naranjo, A.: 'Economic Risk Factors and Commercial Real Estate Returns', Journal of Real Estate Finance and Economics 14(3), (1997) 283-307.

Liu, C.H. and Mei, J.: 'The Predictability of Returns on Equity REITs and their Co-movement with other Assets', Journal of Real Estate Finance and Economics 5, (1992) 401-18. 
Lucas R. E. Jr.: ‘Asset prices in an Exchange Economy’, Econometrica, 46 (1978) 1429-1445

Marsh T., Merton R.: 'Dividend Variability and Variance Bounds Tests for the Rationality of Stock Market Prices', American Economic Review (1986) 76, 483-498

Mattey J., Meese R.: 'Empirical Assessment of Present Value Relations', Econometric Reviews, 5 (1986) $431-450$

McCue, T.E. and Kling, J.L.: 'Real Estate Returns and the Macroeconomy: Some Empirical Evidence from Real Estate Investment Trust Data, 1972-1991', Journal of Real Estate Research 9(3) (1994) 5-32.

Santoni G. J.: 'The Great Bull Markets 1924-29 and 1982-87: Speculative Bubbles or Economic Fundamentals?', Federal Reserve Bank of St. Louis (1987) 16-29

Scott, L.O.: 'Do Prices reflect market fundamentals in Real Estate Markets?', Journal of Real Estate Finance and Economics, 3 (1990) 5-23.

Shiller Robert J.: ‘Market Volatility’, MIT Press, Cambridge Massachusetts, Fifth Edition (1997)

Shiller R. J: 'Do Stock Prices move too much to be Justified by subsequent Changes in Dividends', American Economic Review (1981) 71, 421-36

Sirkin, G.: 'The Stock Market of 1929 Revisited: A Note', Business History Review, 80 (1975) 223-231

Summers L. H: 'Does the stock Market Rationally Reflect Fundamental Values?', The Journal of Finance, 41 (1986) 591-603

West, K.D.: 'A Specification Test for Speculative Bubbles' The Quarterly Journal of Economics, August (1987), 553-80. 